1 School of Dentistry, University of Passo Fundo, Passo Fundo, RS, Brazil;

2 College of Dentistry and Dental Clinics, University of lowa, lowa City, IA, United States.
Corresponding author:

Matheus Albino Souza, PostGraduate Program in Dentistry, University of Passo Fundo, BR 285/ São José, Building A7, Suite 2, Zip code: 99052-900, Passo FundoRS-Brazil. Telephone: +55 543316 8402. E-mail: matheus292@yahoo. com.br or matheussouza@upf.br

Received: March 14, 2018 Accepted: September 29, 2018

\section{Effect of chemical and natural irrigant solutions on microhardness of root dentin- an in vitro study}

\author{
Caren Taffarel ${ }^{1}$, Fernanda Duda Bonatto ${ }^{1}$, Filipe do \\ Carmo Bonfante ${ }^{1}$, Huriel Scartazzini Palhano ${ }^{1}$, Cristina \\ de Mattos Pimenta Vidal', Doglas Cecchin ${ }^{1}$, Matheus \\ Albino Souza ${ }^{1 *}$
}

Aim: Modifications in the mechanical properties of dentin may reduce the fracture resistance of tooth, especially after endodontic treatment. The aim of present study was to evaluate the effect of the irrigation with different root canal irrigants on the microhardness of root dentin. Methods: The coronal portion of 60 single-rooted bovine incisors was sectioned and the pulpal tissue removed using endodontic $\mathrm{K}$-files. The roots were cut transversely to obtain 2 fragments, which were embedded in acrylic resin and randomly distributed into six groups $(n=20)$ according to the irrigation protocol: distilled water (DW) (control); $2 \%$ chlorhexidine solution ( $\mathrm{CHX}$ ); $6 \%$ sodium hypochlorite $(\mathrm{NaOCl}) ; 6 \%$ calcium hypochlorite $\left(\mathrm{Ca}[\mathrm{OCl}]_{2}\right)$; QMix; and $6.5 \%$ grape seed extract solution (GSE). The solutions were kept in contact with the root dentin specimens for $30 \mathrm{~min}$. After that, irrigation with $5 \mathrm{~mL}$ of DW was performed. The Vickers microhardness was determined by performing three indentations in all specimens, using 300-g load and 20-second dwell time. The first indentation was made $1.000 \mu \mathrm{m}$ from the root canal entrance, and two other indentations were made at a distance of $200 \mu \mathrm{m}$ from each other. The microhardness value for each specimen was obtained as the average of the results for the three indentations. Data were statistically analyzed using oneway ANOVA with $5 \%$ significance level. Results: All the tested irrigant solutions maintained the same microhardness level of the root dentin when compared to the control group, with no statistically significant differences between them $(p<0.05)$ Conclusion: The tested irrigant solutions did not present ability to modify the microhardness of root dentin.

Keywords: Calcium hypochlorite. Chlorhexidine. Grape seed extract. Sodium hypochlorite. Hardness. 


\section{Introduction}

Microorganisms and their products are the main etiological factors for pulpal and periapical diseases, playing a significant role in the induction and progression of these conditions ${ }^{1}$. Chemical auxiliary substances are used to promote bacterial elimination along with mechanical instrumentation of the root canals during endodontic treatment. Sodium hypochlorite $(\mathrm{NaOCl})$ is the most commonly used irrigant due to its broad antimicrobial spectrum ${ }^{2}$ and ability to promote organic tissue dissolution ${ }^{3}$. However, $\mathrm{NaOCl}$ has presented some disadvantages after its use as endodontic irrigant, such as disintegration of dentin collagen ${ }^{4}$, decreasing of dentinal flexural strength and elasticity modulus; ; and modifications in the microhardness of dentinal structure $^{6,7}$. Due to the adverse effects promoted by this irrigant solution on mechanical properties of dentin, some alternatives have been researched in endodontics to be used as chemical auxiliary substance during the chemomechanical preparation.

Chlorhexidine digluconate $(\mathrm{CHX})$ has been suggested as an auxiliary chemical substance in endodontic treatment because of its antimicrobial activity ${ }^{8}$ and substantivity $^{9}$. Another advantage of using $\mathrm{CHX}$ as auxiliary chemical substance is that it does not interfere with collagen in the organic matrix of root dentin 4 . However, some studies in the literature have reported decrease of dentin microhardness when irrigated with $2 \% \mathrm{CHX}^{10}$. QMix (Dentsply, Tulsa, OK, USA) has also been used as irrigant solution in endodontics, being composed by EDTA, chlorhexidine (CHX) and a surfactant agent ${ }^{11}$. Although the presence of EDTA in its composition, QMix does not promote dentinal erosion $^{12}$. Moreover, the presence of a surfactant agent decreases the surface tension and increases the wettability ${ }^{13}$, improving the effectiveness of penetration in the depth of dentinal tubules.

More recently, calcium hypochlorite $\left(\mathrm{Ca}[\mathrm{OCl}]_{2}\right)$ has been investigated in endodontics, presenting an effective antimicrobial action against Enterococcus faecalis ${ }^{14}$, ability to promote organic tissue dissolution ${ }^{15}$, chemical stability ${ }^{16}$ and biocompatibility ${ }^{17}$. In the other hand, the use of natural compounds such as grape seed extract (GSE) in endodontics was proposed and it is based on presence of proanthocyanidins (PAC), which have antimicrobial properties ${ }^{18}$. Some PAC-rich plant extracts have great applicability in the dental field for enhancement of dentin biomechanical properties and biostability ${ }^{19}$. In addition, Cecchin et al. ${ }^{18}$ showed that GSE does not harm dentin mechanical properties and it appears to be an alternative for the commonly used chemical irrigants. However, there are no studies in the literature regarding the use of $\mathrm{Ca}(\mathrm{OCl})_{2}$ or GSE and its influence on microhardness of root dentin.

Thus, the purpose of the present study was to evaluate, in vitro, the influence of different irrigant solutions on microhardness of root dentin. The tested null hypothesis was that none of the tested irrigant solutions promotes significant reduction in the microhardness of the root dentin.

\section{Materials and Methods}

This study was approved by the Ethics Committee of the University of Passo Fundo (Passo Fundo, RS, Brazil), under protocol 025/2015. 


\section{Specimen preparation}

Sixty freshly extracted bovine incisors were collected and stored in $4 \%$ formalin (Royal Plás, Curitiba, PR, Brazil) for no longer than 72 hours. Dental crowns were sectioned with a diamond saw $(\# 911 \mathrm{H}$, Brasseler, Savannah, GA, USA) set at 20,000 rpm with a water coolant to obtain $15-\mathrm{mm}$ length roots. All roots were prepared using the same protocol in order to remove pulp tissue. The cervical third was prepared using a Largo \#4 drill (Dentsply-Maillefer, Ballaigues, Switzerland). The working length was established by introducing a K-file \#10 (Dentsply-Maillefer) in the canal until its tip was visualized at the apical foramen. From this measurement, $1 \mathrm{~mm}$ was subtracted, establishing the working length. Then, the root canals were prepared at the working length by serial instrumentation with hand $\mathrm{K}$-files, starting with \#30 K-file and finishing with \#45 K-file using DW as irrigant solution. The root canal was filled with DW using a $5-\mathrm{mL}$ syringe with a 19-G needle before use of each instrument. The needles were centered within the canal $3 \mathrm{~mm}$ short of the working length. After the use of each instrument, irrigation with $5.0 \mathrm{~mL}$ of DW was performed and the irrigant solution was renewed into the root canal until the complete pulp tissue removal. All root canals were dried with \#45 size absorbent paper points (Tanari, Manaus, AM, Brazil). Two Iongitudinal grooves were made in the external root surface using a water cooling diamond disc (Buehler, Lake Bluff, Illinois, EUA) without reaching the canal space. Subsequently, the roots were split into two halves with a hammer and chisel, providing two specimens from each root. The resulting 120 specimens were fixed in acrylic resin blocks (JET - Clássico, Campo Limpo, SP, Brazil), ground and polished with silicon carbide abrasive papers (180, 320, and 600 grit) and $0.25-\mathrm{mm}$ diamond polishing papers (Metkon, Bursa, Turkey) under DW to remove any surface scratches.

\section{Irrigation protocols}

The 120 specimens were randomly divided into 6 groups $(n=20)$ according to irrigant solution: distilled water (DW) (Declomiquis, São Paulo, SP, Brazil); 2\% CHX (Natupharma, Passo Fundo, RS, Brazil); 6\% NaOCl (Farmaquímica SA Produtos Químicos, Porto Alegre, $\mathrm{RS}, \mathrm{Brazil}) ; 6 \% \mathrm{Ca}(\mathrm{OCl})_{2}$ (Farmaquímica SA Produtos Químicos, Porto Alegre, RS, Brazil); QMix (Dentsply Tulsa Dental, Tulsa, OK, United States); and 6.5\% GSE (Mega Natural, Madera, CA, United States). The $2 \% \mathrm{CHX}$ solution was prepared by the chemical pharmacy, while the $\mathrm{NaOCl}, \mathrm{Ca}(\mathrm{OCl})_{2}$ and GSE solutions were prepared immediately before the experiments. A $12 \% \mathrm{NaOCl}$ solution (Farmaquímica SA Produtos Químicos) was titrated and it was diluted in sterilized DW to obtain the concentration of $6 \%$. Both the $\mathrm{Ca}(\mathrm{OCl})_{2}$ and GSE were diluted in DW. The specimens in each group were soaked for 30 minutes in $5 \mathrm{~mL}$ of the irrigant solutions described above, being renewed every 5 minutes. After incubation, the specimens were rinsed with $5 \mathrm{~mL}$ of distilled water, soaked in $17 \%$ EDTA for 1 minute, rinsed again with $5 \mathrm{~mL}$ of distilled water and blotted dry in order to be submitted to dentin microhardness evaluation.

\section{Determination of microhardness on root dentin}

The Durascan 20 Vickers microhardness tester (Shimadzu HMV-2000, Shimadzu Corporation, Kyoto, Japão) measured the dentin microhardness of the root specimens, at a magnification of 40x under a 300-g load and a 20-second dwell time. In each 
sample, three indentations were made along lines parallel to the edge of the root canal lumen. The first indentation was made $1.000 \mu \mathrm{m}$ from the root canal entrance, and two other indentations were made at a distance of $200 \mu \mathrm{m}$ from each other. The hardness value for each specimen was obtained as the average of the results for the three indentations.

\section{Statistical analysis}

SPSS (Statistical Package for Social Science, SPSS, version 17.0, SPSS, Chicago, IL, USA) analyzed the data. Analysis was performed by one-way analysis of variance (ANOVA) Statistical significance level was set at 0.05 .

\section{Results}

Table 1 summarized the Vickers microhardness values (mean and standard deviation) for the tested irrigant solutions. The results revealed that all the tested irrigant solutions maintained the same microhardness level of the root dentin when compared to the control group, with no statistically significant differences between them $(p<0.05)$.

Table 1. Mean and standard deviation of microhardness values (Vickers microhardness number) of the root dentin after treatment with the tested irrigant solutions.

\begin{tabular}{llll}
\hline Group & $\mathrm{n}$ & Mean & Std. deviation \\
\hline 1. Control & 20 & $33.19^{\mathrm{A}}$ & 2.95 \\
\hline 2. $\mathrm{CHX}$ & 20 & $35.08^{\mathrm{A}}$ & 4.03 \\
\hline 3. $\mathrm{NaOCl}$ & 20 & $36.84^{\mathrm{A}}$ & 3.18 \\
\hline $4 . \mathrm{Ca}(\mathrm{OCl})_{2}$ & 20 & $33.31^{\mathrm{A}}$ & 4.56 \\
\hline $5 . \mathrm{QMix}$ & 20 & $36.95^{\mathrm{A}}$ & 3.27 \\
\hline 6. GSE & 20 & $36.32^{\mathrm{A}}$ & 4.01 \\
\hline
\end{tabular}

* Different capital letters indicate significant differences between tested groups $(p<0.05)$.

** $\mathrm{CHX}=2 \%$ chlorhexidine; $\mathrm{NaOCl}=6 \%$ sodium hypochlorite; $\mathrm{Ca}(\mathrm{OCl})_{2}=6 \%$ calcium hypochlorite; $\mathrm{GSE}=6.5 \%$ grape seed extract.

\section{Discussion}

The endodontic therapy uses several irrigant solutions in order to promote an adequate decontamination of the root canal system. However, these chemicals can lead to structural changes on the dentin surface, which may also modify its physical properties ${ }^{4.7}$. The present study investigated if novel irrigant solutions modified dentin mechanical properties in order to propose and support their use in the endodontic therapy as an alternative to the commonly used $\mathrm{NaOCl}$. All irrigants showed similar results and did not interfere with the root dentin microhardness, confirming our tested hypothesis.

In the present study, bovine teeth were used for the dentin microhardness evaluation because is easily available and can be standardised by ensuring the same age and dentinal characteristics, thus reducing some variables reported for human extracted teeth. Furthermore, bovine dentin is similar to human dentin in structure, composition 
and the number of tubules ${ }^{20}$ and has been widely used in in vitro studies. The microhardness was performed in this study since it is an indirect evidence of mineral loss or gain in dental hard tissues ${ }^{21,22}$. In this scenario, the Vickers microhardness test was performed in order to evaluate the influence of different chemical auxiliary substances on microhardness of root dentin. It is less sensitive to surface conditions among the microhardness measurement methods and more sensitive to measurement errors when equal loads are applied ${ }^{23}$. Furthermore, dentin microhardness is related to location of the indentations and its value decreases close to the pulp tissue ${ }^{24}$. Due this fact, indentations were made along lines parallel to the edge of the root canal lumen, being the first indentation located at $1.000 \mu \mathrm{m}$ from the root canal entrance, and two other indentations located at a distance of $200 \mu \mathrm{m}$ from each other, as previously described by Cruz-Filho et al. ${ }^{23}$.

The effect of the same irrigant solutions tested herein on dentin mechanical properties is controversial in the literature ${ }^{7,12}$ and in vitro studies are required to determine clinical recommendations. The microhardness of root dentin depends on the $\mathrm{pH}$ and concentration of the irrigant solution, as well as variables of dentin, such as tubular density, location and age ${ }^{25}$. The number and diameter of dentinal tubules also play an important role in this scenario ${ }^{25}$. Some aspects of the methodology used in our study might have influenced the results and it will be discussed as follows.

First, the effect of different irrigant solutions on the microhardness of root dentin was evaluated with a 30-minutes contact time, in order to simulate the approximate clinical time for the accomplishment of a conventional chemical-mechanical preparation. The root dentin specimens were soaked in 17\% EDTA for 1 minute as a final irrigation protocol. EDTA binds to calcified components of dentin through a chelating mechanism, causing demineralization and softening of dentin. As a consequence, EDTA induces a decrease in root dentin microhardness ${ }^{23,26}$ and might have promoted modifications on all dentin surfaces resulting in similar values for all groups.

The similar dentin microhardness when comparing $\mathrm{NaOCl}$ with the alternative irrigant solutions observed in our study are not in accordance with previous reports in the literature ${ }^{12,27}$. $\mathrm{NaOCl}$ is a chemical auxiliary substance, which is able to dissolve organic components of dentin, as well as magnesium and phosphate ions, at the same time that increases the amount of dentinal carbonate ${ }^{12}$. Moreover, $\mathrm{NaOCl}$ modify the $\mathrm{Ca} / \mathrm{P}$ ratio of the root dentin surface during root canal irrigation ${ }^{28}$. Because the degree of dentin mineralization may affect the hardness profile of the dentin structure $^{21}$, changes in mineral content could be responsible for changes in dentin microhardness after $\mathrm{NaOCl}$ treatment. Differences regarding the volume, incubation time and concentration of irrigant solution, as well as specimen preparation and evaluation methods, could be responsible for the differences between our results and previous reports.

Moreover, in the present study, the use of $2 \% \mathrm{CHX}$ solution did not decrease the microhardness of root dentin, which is not in accordance with previous studies ${ }^{12}$. Although lower concentrations such as $0.2 \%$ showed no effect on microhardness of root dentin as demonstrated by Ari et al. ${ }^{27}$, the endodontic therapy adopt the $2 \%$ concentration. Based on our results, $2 \% \mathrm{CHX}$ is used as an irrigant solution since 
it showed similar results to the control group (DW). An important factor to take into account is that $\mathrm{CHX}$ does not promote morphologic structure alterations in the organic matrix of root dentin ${ }^{4}$. Moreover, some studies have shown that $\mathrm{CHX}$ has beneficial effects on the preservation of resin-dentin bonds by inhibiting the proteoIytic activity of metalloproteinases in the hybrid layer ${ }^{29}$. Therefore, $\mathrm{CHX}$ can help to maintain the quality of the dentin substrate for later filling or restoration of the tooth with resin-based materials.

The use of $\mathrm{Ca}(\mathrm{OCl})_{2}$ as an irrigant solution is supported by the our results since it did not significantly decrease the microhardness of root dentin. Although there are no studies in the literature regarding the influence of $\mathrm{Ca}(\mathrm{OCl})_{2}$ on microhardness of root dentin, Cecchin et al. ${ }^{30}$ revealed that 30 minutes of contact with $\mathrm{Ca}(\mathrm{OCl})_{2}$ did not negatively affect the dentin mechanical properties, such as flexural strength, ultimate tensile strength and fracture resistance. The surface tension of $\mathrm{Ca}(\mathrm{OCl})_{2}$ can help to explain the similar microhardness of root dentin when compared to control group. Surface tension is a physical property, which exert an essential role in the capillarity and droplet formation, being result of the intermolecular attraction between liquid and solid ${ }^{31}$. There is a direct association between wettability of the surface and the surface tension of the solution ${ }^{32}$. Once $\mathrm{Ca}(\mathrm{OCl})_{2}$, has shown low surface tension ${ }^{16}$, it can be suggested that this irrigant solution did not penetrate completely into the dentin and promoted less modifications on the collagen fibrils and consequently on the dentin microhardness.

QMix is a novel endodontic irrigant solution proposed, being a lower aggressive solution than $\mathrm{NaOCl}$ for root canal irrigation. Interestingly, although QMix revealed low ability to decrease the microhardness of root dentin, its components (CHX, EDTA and a surfactant agent) were able to reduce the dentin mechanical properties when used isolated $12,23,25$. Thus, the combined use of these components in QMix provides no deleterious effects on mechanical properties of root dentin, possibly due to the concentration of each component.

In addition, GSE did not induce modifications on microhardness of root dentin. These findings are in accordance with previous studies, where using GSE as irrigant solution did not interfere with dentin mechanical properties ${ }^{18,30}$. In fact, PAC-rich extracts have showed to improve dentin mechanical properties due to their highly stable interaction with dentinal collagen, which occurs by the formation of hydrogen bonds between the protein amide carbonyl and the phenolic hydroxyl group of the polyphenol associated with covalent and hydrophobic bonds ${ }^{33}$. The covalent-like bonds resulted from this interaction can help to preserve the dentin structure. In addition, GSE shows high antimicrobial activity, revealing a higher decontamination potential against Enterococcus faecalis when compared to $\mathrm{NaOCl}^{18}$. However, the evaluation of other properties are necessary to suggest the clinical application of this irrigant solution in endodontics.

Despite the limitations of present study, it can be concluded that the irrigant solutions tested herein did not present ability to modify the microhardness of root dentin. Further studies must be carried out to analyse other desirable properties of $\mathrm{Ca}(\mathrm{OCl})_{2}$, QMix and GSE in order to consolidate these substances as viable alternative irrigants to $\mathrm{NaOCl}$ and $\mathrm{CHX}$ in endodontic therapy. 


\section{Autorship Declaration}

All authors have contributed significantly and all authors are in agreement with the manuscript.

\section{Acknowledgements}

The authors deny any conflicts of interest.

We have no financial affiliation (e.g., employment, direct payment, stock holdings, retainers, consultantships, patent licensing arrangements or honoraria), or involvement with any commercial organisation with direct financial interest in the subject or materials discussed in this manuscript, nor have any such arrangements existed in the past three years. Any other potential conflict of interest is disclosed.

\section{References}

1. Kakehashi S, Stanley HR, Fitzgerald RJ. The effects of surgical exposures of dental pulps in germ-free and conventional laboratory rats. Oral Surg Oral Med Oral Pathol. 1965 Sep;20:340-9.

2. Du T, Wang Z, Shen Y, Ma J, Cao Y, Haapasalo M. Effect of long-term exposure to endodontic disinfecting solutions on young and old Enterococcus faecalis biofilms in dentin canals. J Endod. 2014 Apr;40(4):509-14. doi: 10.1016/j.joen.2013.11.026.

3. Okino LA, Siqueira EL, Santos M, Bombana AC, Figueiredo JA. Dissolution of pulp tissue by aqueous solution of chlorhexidine digluconate and chlorhexidine digluconate gel. Int Endod J. 2004 Jan;37(1):38-41.

4. Moreira DM, Almeida JF, Ferraz CC, Gomes BP, Line SR, Zaia AA. Structural analysis of bovine root dentin after use of different endodontics auxiliary chemical substances. J Endod. 2009 Jul;35(7):1023-7. doi: 10.1016/j.joen.2009.04.002.

5. Marending M, Paqué F, Fischer J, Zehnder M. Impact of irrigant sequence on mechanical properties of human root dentin. J Endod. 2007 Nov;33(11):1325-8.

6. Patil CR, Uppin V. Effect of endodontic irrigating solutions on the microhardness and roughness of root canal dentin: an in vitro study. Indian J Dent Res. 2011 Jan-Feb;22(1):22-7. doi: $10.4103 / 0970-9290.79969$.

7. Aslantas EE, Buzoglu HD, Altundasar E, Serper A. Effect of EDTA, sodium hypochlorite, and chlorhexidine gluconate with or without surface modifiers on dentin microhardness. J Endod. 2014 Jun;40(6):876-9. doi: 10.1016/j.joen.2013.10.041.

8. Ferraz CC, Gomes BP, Zaia AA, Teixeira FB, Souza-Filho FJ. In vitro assessment of the antimicrobial action and the mechanical ability of chlorhexidine gel as an endodontic irrigant. J Endod. 2001 Jul;27(7):452-5.

9. Böttcher DE, Sehnem NT, Montagner F, Fatturi Parolo CC, Grecca FS. Evaluation of the effect of Enterococcus faecalis biofilm on the $2 \%$ chlorhexidine substantivity: an in vitro study. J Endod. 2015 Aug;41(8):1364-70. doi: 10.1016/j.joen.2015.04.016.

10. Oliveira LD, Carvalho CA, Nunes W, Valera MC, Camargo CH, Jorge AO. Effects of chlorhexidine and sodium hypochlorite on the microhardness of root canal dentin. Oral Surg Oral Med Oral Pathol Oral Radiol Endod. 2007 Oct; 104(4):e125-8.

11. Stojicic S, Shen $Y$, Qian W, Johnson B, Haapasalo M. Antibacterial and smear layer removal ability of a novel irrigant, QMiX. nt Endod J. 2012 Apr;45(4):363-71. doi: 10.1111/j.1365-2591.2011.01985.x. 
12. Saghiri MA, Delvarani A, Mehrvarzfar P, Malganji G, Lotfi M, Dadresanfar B, et al. A study of the relation between erosion and microhardness of root canal dentin. Oral Surg Oral Med Oral Pathol Oral Radiol Endod. 2009 Dec;108(6):e29-34. doi: 10.1016/j.tripleo.2009.07.056.

13. Giardino L, Ambu E, Becce C, Rimondini L, Morra M. Surface tension comparison of four common root canal irrigants and two new irrigants containing antibiotic. J Endod 2006 Nov;32(11):1091-3.

14. de Almeida AP, Souza MA, Miyagaki DC, Dal Bello Y, Cecchin D, Farina AP. Comparative evaluation of calcium hypochlorite and sodium hypochlorite associated with passive ultrasonic irrigation on antimicrobial activity of a root canal system infected with Enterococcus faecalis: an in vitro study. J Endod. 2014 Dec;40(12):1953-7. doi: 10.1016/j.joen.2014.08.025..

15. Dutta A, Saunders WP. Comparative evaluation of calcium hypochlorite and sodium hypochlorite on soft-tissue dissolution. J Endod. 2012 Oct;38(10):1395-8. doi: 10.1016/j.joen.2012.06.020.

16. Leonardo NG e S, Carlotto IB, Luisi SB, Kopper PMP, Grecca FS, Montagner F. Calcium Hypochlorite Solutions: Evaluation of Surface Tension and Effect of Different Storage Conditions and Time Periods over pH and Available Chlorine Content. J Endod. 2016 Apr;42(4):641-5. doi: 10.1016/j.joen.2016.01.006.

17. Blattes GBF, Mestieri LB, Böttcher DE, Fossati ACM, Montagner F, Grecca FS. Cell migration, viability and tissue reaction of calcium hypochlorite based-solutions irrigants: an in vitro and in vivo study. Arch Oral Biol. 2017 Jan;73:34-39. doi: 10.1016/j.archoralbio.2016.08.037.

18. Cecchin D, Farina AP, Souza MA, Albarello LL, Schneider AP, Vidal CM, et al. Evaluation of antimicrobial effectiveness and dentine mechanical properties after use of chemical and natural auxiliary irrigants. J Dent. 2015 Jun;43(6):695-702. doi: 10.1016/j.jdent.2015.03.013.

19. Aguiar TR, Vidal CM, Phansalkar RS, Todorova I, Napolitano JG, McAlpine JB, et al. Dentin biomodification potential depends on polyphenol source. J Dent Res. 2014 Apr;93(4):417-22. doi: $10.1177 / 0022034514523783$.

20. Ørstavik D, Haapasalo M. Disinfection by endodontic irrigants and dressings of experimentally infected dentinal tubules. Endod Dent Traumatol. 1990 Aug;6(4):142-9.

21. Arends J, Ten Bosch JJ. Demineralization and remineralization evaluation techniques. J Dent Res. 1992 Apr;71 Spec No:924-8.

22. Panighi M, G'Sell C. Influence of calcium concentration on the dentin wettability by an adhesive. J Biomed Mater Res. 1992 Aug;26(8):1081-9.

23. Cruz-Filho AM, Sousa-Neto MD, Savioli RN, Silva RG, Vansan LP, Pécora JD. Effect of chelating solutions on the microhardness of root canal lumen dentin. J Endod. 2011 Mar;37(3):358-62. doi: 10.1016/j.joen.2010.12.001.

24. Pashley D, Okabe A, Parham P. The relationship between dentin microhardness and tubule density. Endod Dent Traumatol. 1985 Oct;1(5):176-9.

25. Zhang K, Kim YK, Cadenaro M, Bryan TE, Sidow SJ, Loushine RJ, et al. Effects of different exposure times and concentrations of sodium hypochlorite/ethylenediaminetetraacetic acid on the structural integrity of mineralized dentin. J Endod. 2010 Jan;36(1):105-9. doi: 10.1016/j.joen.2009.10.020.

26. De Deus G, Reis C, Fidel S, Fidel R, Paciornik S. Dentine demineralization when subjected to BioPure MTAD: a longitudinal and quantitative assessment. J Endod. 2007 Nov;33(11):1364-8.

27. Ari H, Erdemir A, Belli S. Evaluation of the effect of endodontic irrigation solution on microhardness and the roughness of root canal dentin. J Endod. 2004 Nov;30(11):792-5.

28. Doğan H, Qalt S. Effects of chelating agents and sodium hypochlorite on mineral content of root dentin. J Endod. 2001 Sep;27(9):578-80. 
29. Breschi L, Mazzoni A, Nato F, Carrilho M, Visintini E, Tjäderhane L, et al. Chlorhexidine stabilizes the adhesive interface: a 2-year in vitro study. Dent Mater. 2010 Apr;26(4):320-5. doi: 10.1016/j.dental.2009.11.153.

30. Cecchin D, Soares Giaretta V, Granella Cadorin B, Albino Souza M, Vidal CMP, Paula Farina A. Effect of synthetic and natural-derived novel endodontic irrigant solutions on mechanical properties of human dentin. J Mater Sci Mater Med. 2017 Aug 17;28(9):141. doi: 10.1007/s10856-017-5960-1.

31. Ballal NV, Tweeny A, Khechen K, Prabhu KN, Satyanarayan, Tay FR. Wettability of root canal sealers on intraradicular dentine treated with different irrigating solutions. J Dent. 2013 Jun;41(6):556-60. doi: 10.1016/j.jdent.2013.04.005.

32. Abou-Rass M, Patonai FJ Jr. The effects of decreasing surface tension on the flow of irrigating solutions in narrow root canals. Oral Surg Oral Med Oral Pathol. 1982 May;53(5):524-6.

33. Bedran-Russo AK, Pauli GF, Chen SN, McAlpine J, Castellan CS, Phansalkar RS, et al. Dentin biomodification: strategies, renewable resources and clinical applications. Dent Mater. 2014 Jan;30(1):62-76. doi: 10.1016/j.dental.2013.10.012. 